Check for updates

Cite this: Chem. Commun., 2020, 56,4910

Received 10th January 2020,

Accepted 24th March 2020

DOI: $10.1039 / \mathrm{c} 9 \mathrm{cc} 09888 \mathrm{~g}$

rsc.li/chemcomm

\section{Oxyanion transport across lipid bilayers: direct measurements in large and giant unilamellar vesicles $\dagger$}

\author{
Krzysztof M. Bąk, (D) $\ddagger^{a}$ Bartjan van Kolck, $\ddagger^{b}$ Krystyna Maslowska-Jarzyna, (D) ${ }^{a}$ \\ Panagiota Papadopoulou, (D ${ }^{b}$ Alexander Kros (D) ${ }^{\star b}$ and Michat J. Chmielewski (D) *a
}

\begin{abstract}
A simple di(thioamido)carbazole 1 serves as a potent multispecific transporter for various biologically relevant oxyanions, such as drugs, metabolites and model organic phosphate. The transport kinetics of a wide range of oxyanions can be easily quantified by a modified lucigenin assay in both large and giant unilamellar vesicles.
\end{abstract}

Selective transport of various anions through biological membranes is fundamental to life, as exemplified by cellular respiration, a process which involves facilitated transport of carboxylates, ${ }^{1}$ phosphates $^{2}$ and bicarbonate. ${ }^{3}$ Recently, the development of synthetic molecules that mimic the function of natural anion transporters has attracted significant attention. ${ }^{4}$ Many of these compounds have already been shown to induce programmed cell death, ${ }^{5}$ possess anticancer properties ${ }^{6}$ or inhibit the growth of antibiotic-resistant bacteria strains. ${ }^{7}$

Despite the physiological importance of many oxyanions and the potentially detrimental effects of unselective anion transport on delicate ion homeostasis in cells, ${ }^{8}$ research efforts in this area have mostly been focused on chloride transporters. ${ }^{4}$ The development of artificial carriers for biologically important oxyanions remains a major scientific challenge due to their higher hydration energies, geometrically demanding nature and the lack of direct and convenient methods to follow their transport across lipid membranes in real time. While chloride efflux or influx across the membranes of Large Unilamellar Vesicles (LUVs) can be directly monitored using an appropriate ion selective electrode or a fluorescent probe such as lucigenin, there are no commercially available electrodes or fluorescent sensors for many other biologically relevant anions. Therefore, for example, the transport of bicarbonate, sulfate, and amino acids anions into LUVs has been studied by means of ${ }^{13} \mathrm{C}$ or

\footnotetext{
${ }^{a}$ Faculty of Chemistry, Biological and Chemical Research Centre,

University of Warsaw, Żwirki $i$ Wigury 101, 02-089 Warszawa, Poland.

E-mail: mchmielewski@chem.uw.edu.pl

${ }^{b}$ Leiden Institute of Chemistry, Leiden University, Einsteinweg 55, 2333 CC Leiden, The Netherlands. E-mail: a.kros@chem.leidenuniv.nl

$\dagger$ Electronic supplementary information (ESI) available. See DOI: 10.1039/c9cc09888g \$ Both contributed equally.
}

${ }^{33} \mathrm{~S}$ NMR measurements, which require isotopically enriched anions and provide little kinetic data. ${ }^{9}$ Several indirect assays have also been developed. ${ }^{10}$ Unfortunately, the analytical signal in indirect methods might not be caused by transport of the target species and the receptor in such assays should transport not only the anions of interest, but also $\mathrm{Cl}^{-}$or $\mathrm{OH}^{-}\left(\mathrm{H}^{+}\right)$, what hampers selectivity studies.

Here we demonstrate the transport of a variety of oxyanions trough lipid bilayers using a simple bis(thioamido)carbazole 1. For this we expanded the scope of a popular lucigenin assay to directly measure and compare the transport kinetics of several biologically relevant oxyanions into liposomes (Fig. 1). To the best of our knowledge, $\mathbf{1}$ is the first synthetic anionophore which was shown to transport a non-steroidal anti-inflammatory drug, aspirin, as well as one of the few anionophores that transports organic phosphates across lipid membranes. ${ }^{11}$

Although lucigenin is a popular fluorescent sensor used in chloride transport assays, to our knowledge it has never been used to follow the transport of other anions. ${ }^{12}$ Our systematic screening revealed that lucigenin fluorescence is highly

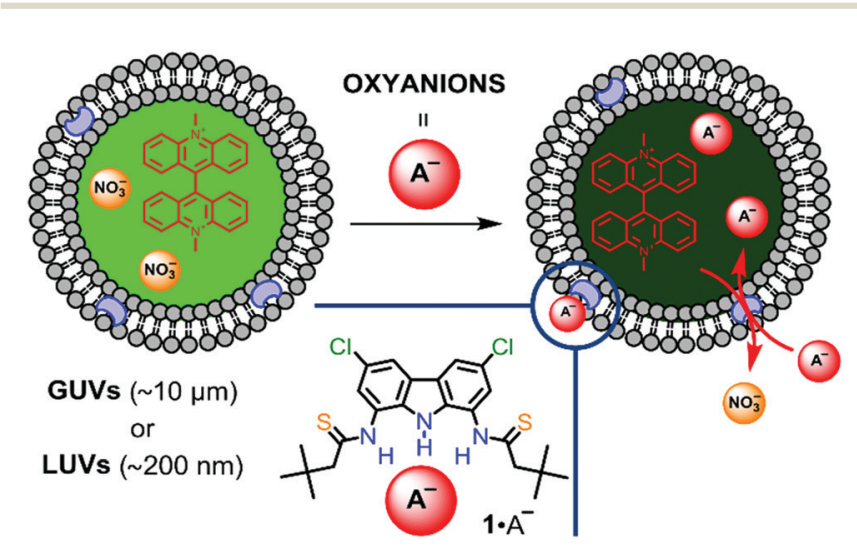

Fig. 1 Schematic representation of anion transport through lipid bilayers of large or giant unilamellar vesicles (LUVs or GUVs) facilitated by di(thioamido)carbazole receptor 1. Encapsulated lucigenin acts as a multipurpose fluorescent sensor for anions. Transporter 1 exchanges internal nitrate for an external anion, which leads to quenching of lucigenin fluorescence. 


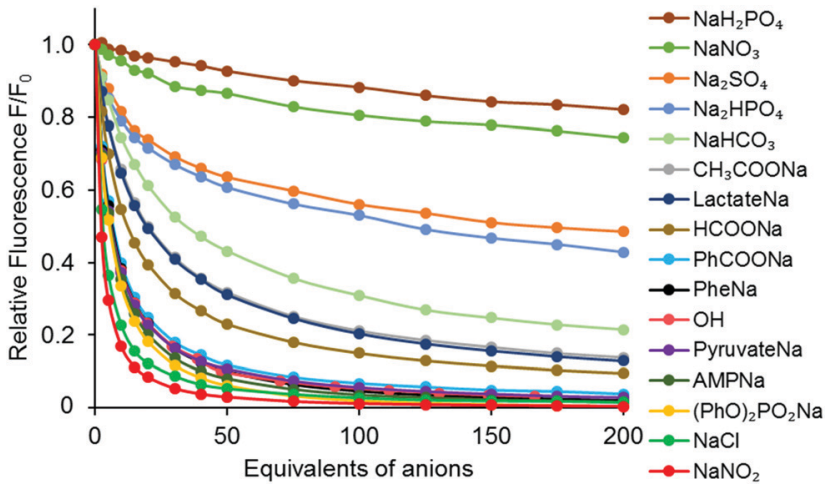

Fig. 2 Fluorescence titration curves of lucigenin $\left(0.8 \mathrm{mM}\right.$ in $\mathrm{H}_{2} \mathrm{O}$ ) quenching with various anions. Excitation: $455 \mathrm{~nm}$, emission: $505 \mathrm{~nm}$.

sensitive to a variety of biologically important oxyanions, such as nucleotides, metabolites, drugs and deprotonated amino acids (Fig. 2). At the same time, it is not significantly quenched by nitrate which is commonly used as a medium in anion transport assays. This enabled us to directly measure transmembrane transport kinetics of a whole range of negatively charged species using lucigenin-filled vesicles.

To validate the new method, we used Giant Unilamellar Vesicles (GUVs). ${ }^{13}$ Unlike more popular LUVs, single GUVs can be directly observed in real time using an optical microscope due to their large size $(10-40 \mu \mathrm{m})$, which is comparable to mammalian cells. This provides an excellent control over their size, lamellarity and stability, all of which heavily influence transmembrane transport.

Since GUVs have surface to volume ratios $c a .2$ orders of magnitude lower than LUVs, the transport rates in GUVs are much slower than in LUVs. Therefore, a particularly active transporter was needed to demonstrate oxyanion transport using this assay. Recently, we have shown that 1,8-diamidocarbazoles display outstanding affinity for oxyanions and are also active chloride transporters, although suffer from poor solubility. ${ }^{14}$ To avoid solubility issues during pre-incorporation of carrier into the vesicle membrane, we designed di(thioamide) $\mathbf{1}$, having both $t$-Bu and $\mathrm{C}=\mathrm{S}$ groups for improved solubility.

To check the suitability of $\mathbf{1}$ for GUV transport assay, we first measured the transport of $\mathrm{Cl}^{-}$anions. In a typical experiment, GUVs were grown in the presence of $\mathrm{NaNO}_{3}(225 \mathrm{mM})$, sucrose $(200 \mathrm{mM})$ and lucigenin $(0.8 \mathrm{mM})$ from a lipid mixture containing 1-palmitoyl-2-oleoylphosphatidylcholine (POPC) and cholesterol in $7: 3$ ratio, di(thioamide) 1 (0.5 mol\%), and rhodamine B labelled lipid $(0.1 \mathrm{~mol} \%)$. Next, the GUVs were transferred to a microscope chamber and imaged using a confocal fluorescence microscope $\left(\lambda_{\mathrm{ex}}^{\text {luc }}=488 \mathrm{~nm} / \lambda_{\mathrm{ex}}^{\text {rhod B }}=532 \mathrm{~nm}\right)$. Finally, anions were added to obtain a concentration of $100 \mathrm{mM}$.

Upon the addition of $\mathrm{NaCl}$ to the GUV suspension, unencapsulated lucigenin was instantly quenched, followed by a rapid fluorescence drop inside the vesicles. After $c a .100 \mathrm{~s}$ the fluorescence intensity diminished to less than $10 \%$ of its initial value and no further changes were observed (Fig. 3). Confocal images revealed that the GUVs remained intact throughout the experiment, which means that the disappearance of lucigenin fluorescence was not caused by vesicle bursting (Fig. 3).

Additionally, leakage was ruled out by a separate control experiment using vesicles loaded with carboxyfluorescein. In control experiments with vesicles lacking the transporter in the membrane, only minor changes of lucigenin fluorescence were observed, indicating that both spontaneous anion transport and photobleaching are negligible on the transport experiment timescale. Thus, $\mathbf{1}$ proved to be a very active chloride transporter and promising candidate to test the lucigenin@GUVs assay in the transport of non-halide anions.

As model carboxylates, we selected benzoate and aspirin. Benzoate is a commonly used food preservative, while aspirin is a prominent non-steroidal anti-inflammatory drug (NSAID). Many NSAIDs, as well as other pharmaceuticals, predominantly exist in their anionic forms at physiological $\mathrm{pH}$ and typically are unable to freely cross biological membranes. Although these drugs diffuse through lipid bilayers in their protonated forms, carrier-mediated and active uptake of their anionic forms might also play a significant role. ${ }^{15}$ Thus, artificial anion carriers might become useful in drug delivery.

1 turned out to be a very potent carboxylate carrier (Fig. 3 and ESI $\dagger$ Fig. S2.6). Benzoate was transported on a similar time scale as chloride (100 s); however, aspirin transport was even faster and reached equilibrium within $50 \mathrm{~s}$. Aspirin transport was so rapid that additional experiments with lower transporter loading $(0.25 \mathrm{~mol} \%)$ and lower anion concentration $(50 \mathrm{mM})$ were necessary to quantify its rate (vide infra). Control experiments in the absence of $\mathbf{1}$ in the GUV membrane showed that fluorescence changes inside the vesicles were negligible under these conditions both for benzoate and aspirin anions. To the best of our knowledge, di(thioamide) $\mathbf{1}$ is the first low molecular weight artificial carrier for anionic drugs.

Amino acid transport across lipid bilayers is gaining increasing attention recently because of its crucial role in absorption of nutrients, cell volume regulation and in nervous system. ${ }^{16,17}$ Our initial screening revealed that both deprotonated phenylalanine and serine were able to quench lucigenin fluorescence (Fig. 2). Unfortunately, fast and irreversible decomposition of lucigenin was observed under confocal microscope in both cases, with concomitant formation of insoluble luminescent particles. It is worth noting that this process could have been easily overlooked in classic LUV assays. The insoluble particles were identified as 10,10'-dimethyl-9, $9^{\prime}$-biacridinylidene, a product of lucigenin reduction by the amino acids. ${ }^{18}$ Therefore, a more chemically stable probe needs to be developed for studying the transport of deprotonated amino acids.

Organic phosphates with aromatic rings and/or $\mathrm{NH}_{2}$ groups, such as nucleotides AMP or cAMP, are also very efficient quenchers of lucigenin (Fig. 2 and ESI $\dagger$ Fig. S2.2). Using monoanionic diphenyl phosphate as a model, we observed rapid transport with full equilibration reached within less than $100 \mathrm{~s}$. Control experiments revealed that diphenyl phosphate relatively easily penetrates lipid bilayers even at the basic $\mathrm{pH}$ employed in the experiment $(\mathrm{pH}=10), \S$ but the process is significantly accelerated in the presence of $\mathbf{1}$. This suggests that the di(thioamido)carbazole 

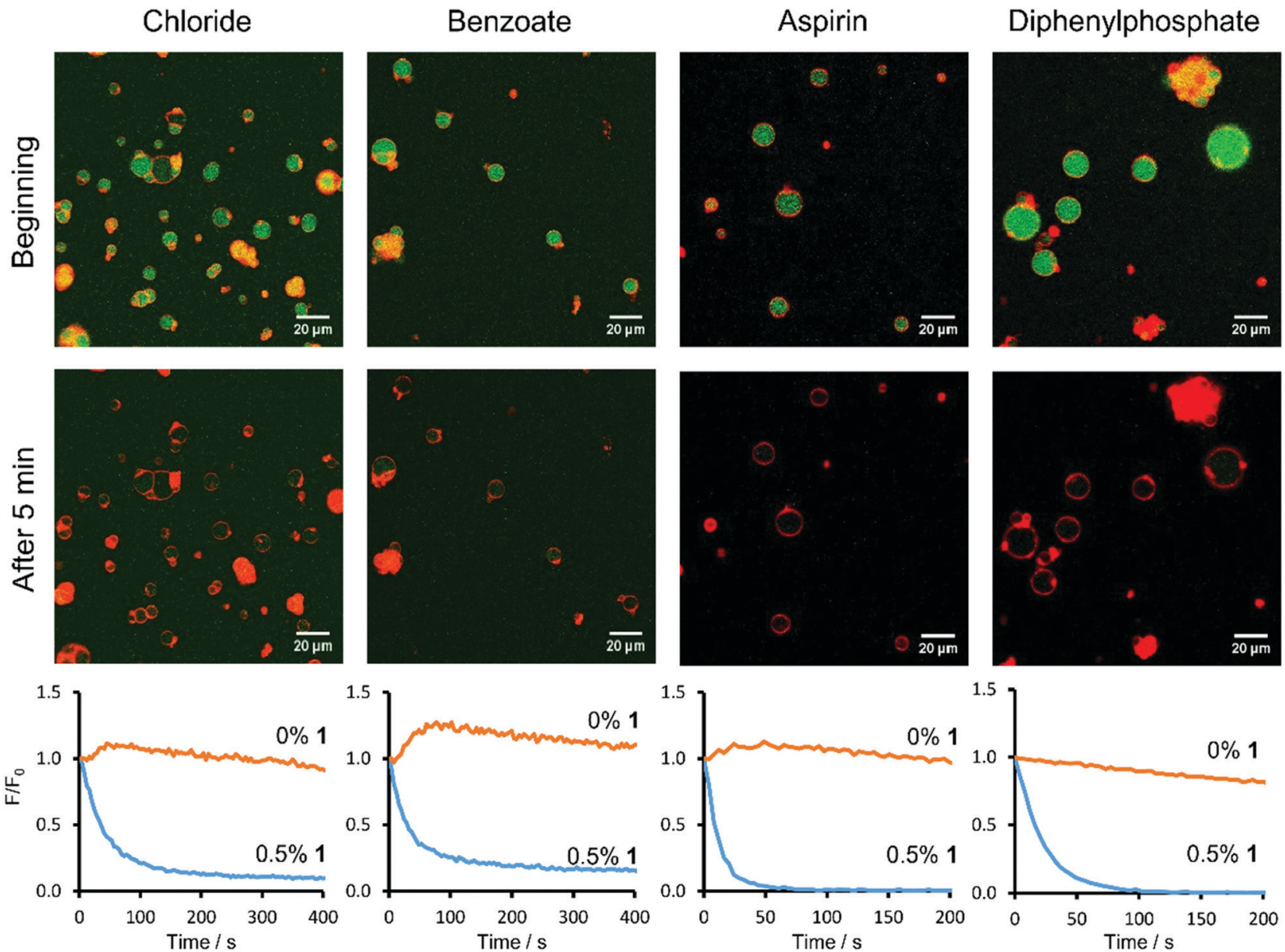

Fig. 3 Confocal fluorescence microscopy images of lucigenin-containing GUVs incorporating 0.5 mol\% of transporter 1 in their membrane before (top) and 5 minutes after (middle) the addition of various anions. Microscopy images overlay results from two channels: $\lambda_{\mathrm{ex}}=488 \mathrm{~nm}$ used to visualize lucigenin (green) inside vesicles and $\lambda_{\mathrm{ex}}=532 \mathrm{~nm}$ used to visualize rhodamine B (red) in bilayers. Yellow colour results from overlay of the green and red fluorescence. The bottom images show the averaged traces of relative fluorescence intensity $\left(F / F_{0}\right)$ of lucigenin after addition of anions $(100 \mathrm{mM})$ to GUVs without transporter (orange) and with $0.5 \mathrm{~mol} \%$ of 1 in the membrane (blue).

moiety might be useful for the construction of more complex and specific phosphate transporters in the future.

To quantify and compare the rate of transport for various anions, the experimental fluorescent decay curves were fitted with exponential functions and their half-life values were compared. This gave the following selectivity order: aspirin $\left(t_{1 / 2}=8 \mathrm{~s}\right)>\left(\mathrm{PhO}_{2} \mathrm{PO}_{2}^{-}\left(t_{1 / 2}=16 \mathrm{~s}\right)>\mathrm{PhCOO}^{-}\left(t_{1 / 2}=23 \mathrm{~s}\right)>\right.$ $\mathrm{Cl}^{-}\left(t_{1 / 2}=29 \mathrm{~s}\right)$. Thus, the lucigenin quenching assay enables a systematic structure-activity studies of a range of anions and opens doors to the development of selective anion transporters.

Successful validation of the method under microscopic control encouraged us to use lucigenin to study oxyanion transport in the classic, spectrofluorometric LUVs assay. Since LUVs $(c a .200 \mathrm{~nm})$ are much smaller than GUVs $(c a .10 \mu \mathrm{m})$, considerably lower concentrations of the anionophore $(0.005 \mathrm{~mol} \%$ vs. $0.5 \mathrm{~mol} \%)$ and studied anions ( $25 \mathrm{mM}$ vs. $100 \mathrm{mM}$ ) were sufficient to measure fluorescence decay of the vesicle suspension. For benzoate, aspirin and diphenylphosphate, equilibrium was reached within $300 \mathrm{~s}$, while for chloride and pyruvate - an important metabolite - it took over $800 \mathrm{~s}$. $\uparrow$ However, control experiments with
LUVs having no transporter inside their membrane showed that the first three anions significantly diffused across the lipid bilayer even without assistance from an anionophore (ESI, $\dagger$ Fig. S2.21). The free diffusion of anions could be neglected in GUVs due to two orders of magnitude higher anionophore concentration, whereas in LUVs it had to be subtracted mathematically to yield the transporter activity (see ESI $\dagger$ for details). This led to the selectivity order which is similar to the one obtained in GUVs, despite the drastically different experimental conditions for the two assays: $(\mathrm{PhO})_{2} \mathrm{PO}_{2}^{-}\left(t_{1 / 2}=35 \mathrm{~s}\right)>\mathrm{PhCOO}^{-}\left(t_{1 / 2}=73 \mathrm{~s}\right)>$ aspirin $\left(t_{1 / 2}=112 \mathrm{~s}\right)>$ pyruvate $\left(t_{1 / 2}=261 \mathrm{~s}\right)>\mathrm{Cl}^{-}\left(t_{1 / 2}=364 \mathrm{~s}\right) \gg$ $\mathrm{HCO}_{3}{ }^{-}$. The only difference is the relative position of aspirin, which shifts significantly in the LUV assay because the overall transport is dominated by free diffusion in this case. $\|$

To shed some light on the mechanism of anion transport by 1, we performed additional control experiments in which the relatively lipophilic $\mathrm{NO}_{3}{ }^{-}$anions were replaced by highly hydrophilic $\mathrm{SO}_{4}{ }^{2-}$ in both internal and external media. No significant anion transport was detected under these conditions, ruling out the $\mathrm{Na}^{+} / \mathrm{A}^{-}$symport mechanism as well as unspecific transport 
due to membrane destabilization by 1 . This leaves the $\mathrm{A}^{-} / \mathrm{NO}_{3}{ }^{-}$ exchange as the most likely mechanism for the transport activity displayed by 1 .

In conclusion, we have demonstrated that lucigenin can be used as a multipurpose fluorescent probe for studying the transport of many biologically important oxyanions, including drugs, metabolites and nucleotides. Both GUVs and LUVs loaded with lucigenin were successfully used to quantify and compare the transport rates of various anions through lipid membranes. These simple assays will aid the screening of large libraries of anions and transporters, likely yielding new insights into the structural demands for selective anion transport across lipid membranes and paving the way for novel biomedical applications, such as drug delivery. In addition, we have also shown that $\mathbf{1}$ not only is an extremely potent chloride transporter, but also facilitates the transport of various oxyanions, such as carboxylates and organic phosphates. Its simple structure, modular design and high transport activity make it a particularly promising leading structure for the construction of more sophisticated anionophores with increased selectivity.

This work was supported by the National Science Centre, Poland (OPUS grant 2018/31/B/ST5/02085 to M. C.) and the Netherlands Organisation of Scientific Research (VICI grant 724.014.001 to A. K.). Part of this study was carried out at the Biological and Chemical Research Centre, University of Warsaw, established within a project co-financed by the European Union through the European Regional Development Fund under the Operational Programme Innovative Economy 20072013. We thank prof. Hennie Valkenier for helpful discussions.

\section{Conflicts of interest}

There are no conflicts to declare.

\section{Notes and references}

$\S$ The influence of $\mathrm{OH}^{-}$transport was excluded through a set of control experiments (see ESI, $\dagger$ Fig. S2.1).

T When loading of 1 was increased to $0.5 \mathrm{~mol} \%$, full equilibration was observed within $100 \mathrm{~s}$.

$\|$ When concentration of $\mathbf{1}$ in LUVs membrane was increased to $0.05 \mathrm{~mol} \%$, transport of benzoate, aspirin and diphenylphopshate was accelerated to such an extent, that it could not be completely separated from the initial fluorescence drop caused by the quenching of residual lucigenin outside of the vesicles. Conditions suitable for direct comparison of all these anions could not be found in the LUV assay, highlighting one more advantage of GUVs.

1 A. P. Halestrap and N. T. Price, Biochem. J., 1999, 343, 281.

2 H. Luecke and F. A. Quiocho, Nature, 1990, 347, 402.

3 E. Cordat and J. R. Casey, Biochem. J., 2009, 417, 423.
4 P. A. Gale, J. T. Davis and R. Quesada, Chem. Soc. Rev., 2017, 46, 2497; N. Busschaert, C. Caltagirone, W. Van Rossom and P. A. Gale, Chem. Rev., 2015, 115, 8038; A. Vargas Jentzsch, A. Hennig, J. Mareda and S. Matile, Acc. Chem. Res., 2013, 46, 2791; P. A. Gale, R. Pérez-Tomás and R. Quesada, Acc. Chem. Res., 2013, 46, 2801; G. W. Gokel and S. Negin, Acc. Chem. Res., 2013, 46, 2824; S. Matile, A. Vargas Jentzsch, J. Montenegro and A. Fin, Chem. Soc. Rev., 2011, 40, 2453; J. T. Davis, O. Okunola and R. Quesada, Chem. Soc. Rev., 2010, 39, 3843; N. L. Mora, A. Bahreman, H. Valkenier, H. Li, T. H. Sharp, D. N. Sheppard, A. P. Davis and A. Kros, Chem. Sci., 2016, 7, 1768; H. Li, H. Valkenier, A. G. Thorne, C. M. Dias, J. A. Cooper, M. Kieffer, N. Busschaert, P. A. Gale, D. N. Sheppard and A. P. Davis, Chem. Sci., 2019, 10, 9663.

5 N. Busschaert, S.-H. Park, K.-H. Baek, Y. P. Choi, J. Park, E. N. W. Howe, J. R. Hiscock, L. E. Karagiannidis, I. Marqes, V. Félix, W. Namkung, J. L. Sessler, P. A. Gale and I. Shin, Nat. Chem., 2017, 9, 667; T. Saha, A. Gautam, A. Mukherjee, M. Lahiri and P. Talukdar, J. Am. Chem. Soc., 2016, 138, 16443; S.-K. Ko, S. K. Kim, A. Share, V. M. Lynch, J. Park, W. Namkung, W. Van Rossom, N. Busschaert, P. A. Gale, J. L. Sessler and I. Shin, Nat. Chem., 2014, 6, 885.

6 L. A. Jowett, E. N. W. Howe, V. Soto-Cerrato, W. Van Rossom, R. PérezTomás and P. A. Gale, Sci. Rep., 2017, 7, 9397; A. M. Rodilla, L. KorrodiGregório, E. Hernando, P. Manuel-Manresa, R. Quesada, R. Pérez-Tomás and V. Soto-Cerrato, Biochem. Pharmacol., 2017, 126, 23; V. Soto-Cerrato, P. Manuel-Manresa, E. Hernando, S. Calabuig-Fariñas, A. MartínezRomero, V. Fernández-Dueñas, K. Sahlholm, T. Knöpfel, M. GarcíaValverde, A. M. Rodilla, E. Jantus-Lewintre, R. Farràs, F. Ciruela, R. Pérez-Tomás and R. Queasada, J. Am. Chem. Soc., 2015, 137, 15892; B. D. de Greñu, P. I. Hernández, M. Espona, D. Quiñonero, M. E. Light, T. Torroba, R. Pérez-Tomás and R. Quesada, Chem. - Eur. J., 2011, 17, 14074.

7 A. I. Share, K. Patel, C. Nativi, E. J. Cho, O. Francesconi, N. Busschaert, P. A. Gale, S. Roelens and J. L. Sessler, Chem. Commun., 2016, 52, 7560; C. R. Elie, G. David and A. R. Schmitzer, J. Med. Chem., 2015, 58, 2358.

8 X. Wu, E. N. W. Howe and P. A. Gale, Acc. Chem. Res., 2018, 51, 1870; X. Wu, L. W. Judd, E. N. W. Howe, A. M. Withecombe, V. Soto-Cerrato, H. Li, N. Busschaert, H. Valkenier, R. Pérez-Tomás, D. N. Sheppard, Y.-B. Jiang, A. P. Davis and P. A. Gale, Chem, 2016, 1, 127.

9 N. Busschaert, L. E. Karagiannidis, M. Wenzel, C. J. E. Haynes, N. J. Wells, P. G. Young, D. Makuc, J. Plavec, K. A. Jolliffe and P. A. Gale, Chem. Sci., 2014, 5, 1118; J. T. Davis, P. A. Gale, O. A. Okunola, P. Prados, J. C. Iglesias-Sánchez, T. Torroba and R. Quesada, Nat. Chem., 2009, 1, 138.

10 S. Matile and N. Sakai in Analytical Methods in Supramolecular Chemistry, ed. C. A. Schalley, Wiley-VCH, Weinheim, 2007, pp. 391-418.

11 Z. Zawada, A. Tatar, P. Mocilac, M. Buděšínský and T. Kraus, Angew. Chem., Int. Ed., 2018, 57, 9891; V. Janout, B. Jing and S. L. Regen, J. Am. Chem. Soc., 2005, 127, 15862; V. Janout, B. Jing, I. V. Staina and S. L. Regen, J. Am. Chem. Soc., 2003, 125, 4436.

12 H. Valkenier, L. W. Judd, H. Li, S. Hussain, D. N. Sheppard and A. P. Davis, J. Am. Chem. Soc., 2014, 136, 12507; B. A. McNally, A. V. Koulov, B. D. Smith, J. B. Joos and A. P. Davis, Chem. Commun., 2005, 1087.

13 H. Valkenier, N. L. Mora, A. Kros and A. P. Davis, Angew. Chem., Int. Ed., 2015, 54, 2137.

14 K. M. Bąk, K. Chabuda, H. Montes, R. Quesada and M. J. Chmielewski, Org. Biomol. Chem., 2018, 16, 5188.

15 P. D. Dobson and D. B. Kell, Nat. Rev. Drug Discovery, 2008, 7, 205. 16 X. Wu, N. Busschaert, N. J. Wells, Y.-B. Jiang and P. A. Gale, J. Am. Chem. Soc., 2015, 137, 1476 and references cited therein.

17 J. Sánchez-Quesada, H. S. Kim and M. R. Ghadiri, Angew. Chem., Int. Ed., 2001, 40, 2503; L. Chen, W. Si, L. Zhang, G. Tang, Z.-T. Li and J.-L. Hou, J. Am. Chem. Soc., 2013, 135, 2152.

18 K. Maeda, Y. Kashiwabara and M. Tokyama, Bull. Chem. Soc. Jpn., 1977, 50, 473. 